\title{
Do adjectives exhaust the personality lexicon? A psycholexical study of the Lithuanian language
}

\author{
Ana Ivanova ${ }^{1 \cdot A, B, C, D, E, F}$, Oleg Gorbaniuk $k^{1,2 \cdot A, D, E}$, Dovile Blekkaityte $e^{3 \cdot B}$, Egle Dovydaityte $e^{3 \cdot B}$, \\ Austeja A. Čepuliene $\dot{e}^{3 \cdot B}$, Greta Mastauskaite $\dot{e}^{3 \cdot B}$, Rokas Ramanauskas ${ }^{3 \cdot B}$, Ugne Furgelyte $\dot{e}^{3 \cdot B}$, \\ Ringaile Slapšinskaitè ${ }^{4 \cdot B}$ \\ 1: The John Paul II Catholic University of Lublin, Poland \\ 2: University of Zielona Gora, Poland \\ 3: Vilnius University, Vilnius, Lithuania \\ 4: Utrecht University, Utrecht, Netherlands
}

\section{BACKGROUND}

The psycholexical approach is based on the assumption that the most important individual differences that people can observe have been encoded into the natural language. Thus, by studying the structure of these lexicons, we are able to identify individual differences that are universal across cultures as well as dimensions that are unique to some of them. The aim of the study was to develop a psycholexical taxonomy of the Lithuanian language including different parts of speech.

\section{PARTICIPANTS AND PROCEDURE}

the authors analysed over 76,000 entries included in a dictionary of Lithuanian and identified 9625 person-descriptive terms: adjectives, attribute-nouns, type-nouns, and participles. The selected lexical material was classified by a team of six judges into 11 subcategories making up six higher-order categories. The authors performed the psychometric validity and consistency of the judges' classification decisions.

\section{RESULTS}

The analysis of proportions between types of lexical units describing dispositional traits showed that nearly $20.00 \%$ of terms in the personality lexicon did not have an adjectival form and were expressed by means of other - morphemically non-redundant - parts of speech.

\section{CONCLUSIONS}

The present study points to the necessity of taking into account various parts of speech describing dispositional traits in order to avoid the error of reductionism; it also contributes to the debate on universals in personality description. The results of the study can be used to determine the structure of the description of individual differences for the Lithuanian personality lexicon, for type-nouns or attribute-nouns, and for non-dispositional categories, including emotions, social effects, and worldview.

\section{KEY WORDS}

personality; individual differences; psycholexical taxonomy; Lithuanian language

CORResPonding Author - Ana Ivanova, The John Paul II Catholic University of Lublin, 14 Aleje Racławickie Street,

20-950 Lublin, Poland, e-mail: anna.iwanowa.kul@gmail.com

AUthors' Contributions - A: Study design - B: Data collection · C: Statistical analysis · D: Data interpretation ·

E: Manuscript preparation · F: Literature search · G: Funds collection

To Cite this ARTICle - Ivanova, A., Gorbaniuk, O., Blèkaitytè, D., Dovydaitytè, E., Čepulienè, A. A., Mastauskaitè, G.,

Ramanauskas, R., Jurgelytè, U., \& Slapšinskaitè R. (2018). Do adjectives exhaust the personality lexicon?

A psycholexical study of the Lithuanian language. Current Issues in Personality Psychology 6(3), 171-180.

RECEIVED 25.09.2017 · REVIEWED 09.11.2017 • ACCEPTED 21.12.2017 • PUBLISHED 09.03.2018 


\section{BACKGROUND}

The diversity of individual differences is infinite, but not all differences between people are equally important from the point of view of individuals' psychological and social functioning. One of the aims of psychology is to systematise these differences in order to identify the characteristics that make it possible to explain and predict human behaviour. The systematisation of individual differences is a divergent problem; consequently, in the trait theory there are many proposals, arrived at both through deduction and theoretical justification of models (e.g., Eysenck, 1953) and through the generalisation of the observed individual differences in exploratory studies (e.g., Cattel, 1945). These proposals differ in terms of the degree of agreement/endorsement in the community of psychologists. The one that stands out among them is the lexical approach, to which we owe the relatively high consistency regarding the number and content of key traits differentiating people in different cultures (Saucier \& Srivastava, 2015). This, however, does not mean that the issue of culturally universal structure of personality traits has been unambiguously resolved. Firstly, only twenty out of a few thousand languages existing in the world have been examined to date, and most of these studies were confined to Indo-European languages. Secondly, the majority of psycholexical studies were restricted to only one of the parts of speech: adjectives. Finally, in a vast majority of cases, analyses have focused on personality lexicon. The scientific taxonomy of individual differences for personality lexicon and non-dispositional lexicon requires systematic research into every language in the world. The aim of this article is to present analyses of the lexicon of individual differences of the Lithuanian language, one of the two Baltic languages that have survived to the present day, covering adjectives, type-nouns, attribute-nouns, and participles.

In the lexical approach, the taxonomy of traits responsible for individual differences is based on the natural language (Allport \& Odbert, 1936; Angleitner, Ostendorf, \& John, 1990). According to the lexical assumption (Goldberg, 1981), the most important individual differences have been encoded into the natural languages. The more significant role a particular characteristic plays in human social functioning, the more likely it is to be expressed in the form of a distinct lexical unit, and the number of these units describing the same individual differences (e.g., synonyms and antonyms) additionally points to the importance of a given characteristic for the users of a given language. Thus, by studying the structure of personality lexicons, we are able to identify traits that are universal across cultures as well as dimensions that are unique to some of them. However, it is impossible to analyse the full lexicon of personality of a given language because no one disposes of that lexicon, and for this reason in psycholexical studies scholars usually use the representative sample of terms (De Raad \& Ostendorf, 1996) selected from a tangible repository of the lexicon of a language. In most of the cases those tangible repositories are dictionaries (De Raad \& Mlačić, 2017).

Historically, the earliest research on the lexicon of individual differences was conducted intuitively and not very systematically, for example, Baumgartner's, (as cited in John, Angleitner, \& Ostendorf, 1988) or Galton's (1884) study; it was not until the psycholexical analysis of the English language (Allport \& Odbert, 1936) that a study was performed based on more coherent methodological rules. The scholars used a dictionary containing 400,000 entries as the most reliable and representative source of English lexicon; they also involved three judges in the selection of descriptors, which enabled them to make the term selection procedure more objective. The selection yielded 17,953 morphologically unique adjectives and nouns describing individual differences, which were then classified into four general categories: personal traits, temporary states, social evaluations, and metaphorical and doubtful terms. Thus constructed, the list of person-descriptive terms was used in subsequent studies (Goldberg, 1982; Norman, 1967); based on its short version, researchers identified the Big Five (Goldberg, 1990) and the Big Six (Ashton, Lee, \& Goldberg, 2004) in English. In the late 1970 s, scholars began to analyse the psycholexical structure of other languages (Angleitner et al., 1990; Brokken, 1978; Hofstee, 1976); new ones are added to the group of examined lexicons every few years.

The optimal standards of psycholexical taxonomy, ensuring the replicability and cross-cultural comparability of studies, have been developed thanks to the work of Dutch (Brokken, 1978; Hofstee, 1976) and German scholars (Angleitner et al., 1990). Nowadays, a typical psycholexical study requires the completion of three main stages: (1) the selection of a representative sample of person-descriptive terms, (2) the classification/reduction of selected person-descriptive terms, and (3) the factor analysis of the structure of personality-descriptive terms. Given that the first two stages determine the results of factor analysis, developing a taxonomy plays a crucial role (Peabody \& Goldberg, 1989; Saucier, 1997). In order to lay the ground for the identification of the factor structure of the personality lexicon, it is necessary to make the following steps: (1) to choose the most representative dictionary of the analysed language (i.e., the most complete and up-to-date one), (2) to select the words describing individual differences - namely, person-descriptive terms, (3) to classify the obtained lexical material (German tradition) or to narrow it 
down (Dutch tradition) to personality descriptors (i.e., to descriptors of dispositional traits), and (4) to reduce the list of personality-descriptive terms so as to use it in research in the form of a questionnaire.

What distinguishes Lithuanian from other European languages is the fact that, together with Latvian, it makes up a small but unique group of Baltic languages. The geographical and historical conditions (e.g., Lithuania Minor as part of East Prussia, the Polish-Lithuanian Commonwealth, the years in the Russian partition and under Soviet occupation) naturally led to the interpenetration of Baltic, Slavic, and Germanic languages, but it remains unknown to what extent the Lithuanian lexicon of individual differences succumbed to Slavicisation or Germanisation. Psycholexical research on a language that, on the one hand, belongs to a rare and small group and, on the other hand, was subject to long-term influence of other European languages, may constitute an important step in looking for an answer to the question of which personality traits meet the condition of universality and which ones are specific to Baltic culture and in particular to the Lithuanians.

The previous psycholexical analysis of the Lithuanian language, carried out by Livaniene and De Raad (2016), was based on the Dutch method. In their research, these authors focused on personality-descriptive adjectives with the highest frequency of use. The study revealed that the cross-cultural Big Five was not reproduced in the Lithuanian context. Developing an alternative and independent Lithuanian taxonomy using a different - German - approach might lead to interesting conclusions, as it did, for instance, in the case of the Italian language. The Italian project conducted in accordance with the Dutch methodology (Caprara \& Perugini, 1994) as well as the taxonomy developed under the German approach (Di Blas \& Forzi, 1998) revealed that the "traditional" Big Five was not reproduced exactly in the Italian context. However, there were some discrepancies between the two emic structures of the Italian personality descriptive adjectives (Di Blas \& Forzi, 1998).

Other studies on the structure of Lithuanians' personality traits were conducted in accordance with the psychometric approach and were limited to the adaptation of instruments measuring the five- or six-factor model assumed in advance (Truskauskaite et al., 2012; Žukauskienė \& Barkauskienè, 2006), which does not make it possible to determine the psycholexical structure of the Lithuanian language and join the debate on universals in personality structure. Despite criticism, the cited studies constitute a very important point of reference and inspiration for further inquiry and for the refinement of methodological techniques.

The main aim of the presented study was to develop a taxonomy of the Lithuanian language
- the psycholexical systematisation and classification of person-descriptive terms. The research was strictly exploratory. In order to avoid the error of reductionism, we took into account various parts of speech: adjectives, participles, type-nouns, and attribute-nouns. The adjectival word class comprises terms that describe different qualities of people (see Bolinger, 1980) and is usually regarded to be the most useful word class of person descriptors; however, permanent and/or important human characteristics are also designated by nouns (Wierzbicka, 1986). Although participles have been used only in few psycholexical studies (Allport \& Odbert, 1936; Gorbaniuk et al., 2014a), terms that represent this part of speech derive from verbs and have features of both verbs and adjectives (Quirk et al., 1972). As a result, some participles describe the qualities of a person. The role of participles might be underestimated in psycholexical studies because those adjectival participles that are morphemically non-redundant can help select a more representative sample of person-descriptive lexicon.

The above general objective can be made specific by means of the following research questions:

Q1: How many person-descriptive terms are there in Lithuanian, and what proportion does each type of lexical unit (nouns, adjectives, participles) constitute in this category?

Q2: What is the ratio of personality-descriptive terms to the overall number of person-descriptive terms? Q3: Do personality adjectives exhaust the Lithuanian personality lexicon?

\section{PARTICIPANTS AND PROCEDURE}

To perform the selection and classification of the Lithuanian terms that can be used to describe individual differences, we applied the method developed Angleitner et al. (1990) for the purposes of German language taxonomy. Its main advantage over the competing method used by Livaniene and De Raad (2017) is the categorisation of person-descriptive terms, which opens the way to the systematisation of individual differences in terms of various non-dispositional categories, such as emotional states (Gorbaniuk \& Macheta, 2017), social reactions (Mlačić, 2016; Saucier, 2010), or social attitudes and worldview (Saucier, 2010), as well as making it possible to determine the structure of personality lexicon for type-nouns (Saucier, 2003) or attribute-nouns (Di Blas, 2005). An additional advantage was the experience of two authors in the application of the German approach to the taxonomy of Polish (Gorbaniuk et al., 2011), Belarusian (Gorbaniuk et al., 2014a), Russian (Ivanova et al., 2017), and Ukrainian (Gorbaniuk et al., 2014b). 


\section{THE SELECTION OF PERSON-DESCRIPTIVE TERMS}

In the first step, we selected adjectives, nouns (divided into type-nouns and attribute-nouns), and participles describing human characteristics. The main source of the lexical material was the latest and currently the most complete Dictionary of Modern Lithuanian (Lithuanian Language Institute, 2012-2017; over 76,000 entries). We had consulted the choice of the basis for lexical research with Lithuania's leading linguists.

The selection was performed by eight judges (native users of Lithuanian: one holder of a master's degree in psychology and seven students in the final years of psychological studies), who were thoroughly prepared for this task: after discussing the theoretical background of the study together with the others, each judge independently performed a trial selection of person-descriptive terms from a set of 500 lexical units, which made it possible for the most frequent errors to be detected and discussed. One person (the psychologist) performed the selection of person-descriptive terms from the entire dictionary, and the other seven people analysed their assigned fragments of the dictionary, which was divided into seven equal parts. As a result, the entire lexical material was processed by a minimum of two judges, in accordance with the standard procedure required in lexical taxonomy.

The task of the judges was to perform a selection of all adjectives, nouns (type-nouns and attribute-nouns), and participles that are used to describe individual characteristics and make it possible to differentiate between people. In this stage, all dictionary meanings of entries were taken into account. When making selection decisions, the judges used several test sentences that were meant to facilitate answering the question of whether a given term was person-descriptive. We formulated separate test questions for each lexical unit.

Adjectives and participles:

Jonas is [adjective]? (e.g., hardworking)

How [adjective] am I?

Type-nouns:

Is Jonas [noun]? (e.g. a coward)

Can he/she be called [noun]?

Attribute-nouns:

Jonas's [noun] is extraordinary? (e.g., kindliness)

Does he/she have [noun]?

Moreover, we applied exclusion criteria that are the most often applied in the literature of the subject, namely: (1) terms that refer to all people and do not differentiate between individuals; (2) participles, which do not describe behaviours but point to the consequences of certain events and thus have no psychological significance; (3) terms referring to background, descent, nationality, as well as religious, geographical, or professional affiliation; (4) words referring to parts of the human body; (5) colours; (6) metaphorical terms, which can refer to human characteristics but their person-descriptive meaning is difficult to capture or requires a context.

As a result of the selection, we found 9688 person-descriptive terms in the dictionary.

\section{THE CLASSIFICATION OF PERSON- DESCRIPTIVE TERMS}

The classification of 9688 person-descriptive terms was performed independently by six judges (native users of Lithuanian: one holder of a master's degree in psychology and five holders of a bachelor's degree in psychology), who had been properly trained to do this task. After becoming acquainted with the theoretical foundations and discussing the contents as well as the boundaries of specific categories, all judges together took part in a classification session involving 200 person-descriptive terms, which gave them a better understanding of the definition of each category and a chance to detect the most frequent errors. Next, the judges independently performed a trial classification of a further 167 words, whose validity was rated by comparison to markers representing each category, taken from earlier studies conducted in other countries, for which inter-judge consistency ranged from $90.00 \%$ to $100.00 \%$. Psychometric validity metrics: (a) kappa correlation coefficient and (b) the percentage of valid decisions, were computed for each judge in each of the 11 subcategories and six higher-order categories. The judges whose classification validity was lower than $70.00 \%$ went through retraining and an additional stage of classification validity testing.

As mentioned above, in the present study we used the classification system developed by Angleitner et al. (1990). First, the judges rated (1) the valence of a term using a five-point scale, (2) the familiarity of the term using a $0 / 1$ scale, and (3) the person relevance of the term using a $0 / 1$ scale. Of the person-descriptive terms, $40.64 \%$ were assessed as having negative valence (1.0-2.49 points), $38.37 \%$ as having neutral valence (2.50-3.49 points), and $20.99 \%$ as having positive valence (3.50-5.0 points). When rating familiarity, the judges took into account both their own understanding of the word and its dictionary definition. This allowed a reduction of the negative impact of the limitations of judges' personal vocabulary on the taxonomy. In this stage, the rating of familiarity had only an indicative character for the further research because the judges relied on their own knowledge as well as dictionary definitions. In the present study, none of the terms was excluded 
A. Ivanova, O. Gorbaniuk, D. Blèkaitytė, E. Dovydaitytė, A. A. Čepulienè, G. Mastauskaitė, R. Ramanauskas, U. Jurgelytè, R. Slapšinskaitè

based on this criterion. The main test of familiarity with personality descriptors will be conducted in further studies on a sample of university students. Terms unclear to a significant proportion of respondents will be removed from the list. Apart from that, the judges used the $0 / 1$ scale to rate if a particular word was a person-descriptive term. When at least three out of six judges decided that a term was not a person descriptor, the word was excluded from the list. As a result, we removed 63 terms, which means this stage led to a reduction from 9688 to 9625 terms. In the next step, 9625 person-descriptive were classified into one of 11 subcategories making up six higher-order categories: (1) dispositions; (1a) temperament and character; (1b) abilities, talents, or their absence; (2) temporary conditions; (2a) experiential states: emotions, moods, and cognitions; (2b) physical and bodily states; (2c) observable activities; (3) social and reputational aspects; $(3 \mathrm{a})$ roles and relationships; (3b) social effects: reactions of others; (3c) pure evaluations; (3d) attitudes and worldviews; (4) overt characteristics and appearance; (4a) anatomy, constitution, and morphology; (4b) appearance and looks; (5) specific terms: chronic diseases and other specialist terms. Metaphorical terms, which constitute a subcategory of specific terms in the German classification (Angleitner et al., 1990), were grouped into a separate category in the present study: (6) metaphors, otherwise they would make the specific terms category too heterogeneous. Additionally, the judges used the category of (7) non-classifiable terms. Due to the ambiguity of some terms, the judges were allowed to classify the same descriptor into more than one lexical subcategory. A term was eventually assigned to a particular category if it was classified into it by at least four out of six judges.

\section{THE VALIDITY AND CONSISTENCY OF TAXONOMIC DECISIONS}

The validity of classification decisions was assessed by means of two lists, translated from Polish into Lithuanian: the first list contained 167 person-descriptive terms and the other one contained 170. The judges were to classify the 337 adjectives that had

Table 1

Validity and consistency of the decisions of judges

\begin{tabular}{|c|c|c|c|}
\hline \multirow[t]{2}{*}{ Category/subcategory } & \multirow{2}{*}{$\begin{array}{c}\text { Correlation with } \\
\text { the criterion } \\
\kappa\end{array}$} & \multicolumn{2}{|c|}{ Inter-judge consistency } \\
\hline & & $\alpha$ & $r$ \\
\hline 1. Dispositions & .97 & .87 & .52 \\
\hline 1a. Temperament and character & .82 & .86 & .51 \\
\hline 1b. Abilities and talents & .91 & .87 & .53 \\
\hline 2. Temporary conditions & .89 & .91 & .64 \\
\hline 2a. Experiential states & .81 & .91 & .63 \\
\hline 2b. Physical and bodily states & .93 & .89 & .58 \\
\hline 2c. Observable activities & .89 & .72 & .30 \\
\hline 3. Social and reputational aspects & .92 & .92 & .65 \\
\hline 3a. Roles and relationships & .86 & .93 & .69 \\
\hline 3b. Social effects & .88 & .56 & .29 \\
\hline 3c. Pure evaluations & .72 & .82 & .42 \\
\hline 3d. Attitudes and worldviews & .93 & .93 & .70 \\
\hline 4. Overt characteristics and appearance & .98 & .96 & .79 \\
\hline 4a. Anatomy, constitution, and morphology & .93 & .93 & .71 \\
\hline 4b. Appearance and looks & .92 & .94 & .72 \\
\hline $\begin{array}{l}\text { 5. Specific terms: chronic diseases and other } \\
\text { specialist terms }\end{array}$ & - & .91 & .63 \\
\hline 6. Metaphors & .88 & .59 & .29 \\
\hline 7. Non-classifiable & - & .02 & .02 \\
\hline
\end{tabular}

Note. $\mathrm{\kappa}$ - mean correlation with the external criterion, $\alpha$ - inter-judge consistency, $r$ - mean inter-judge correlation. 
been classified into the same subcategory and higher-order category (Angleitner et al., 1990) in a previous study by eight out of nine people (Gorbaniuk et al., 2011). We computed the kappa correlation coefficient by confronting the classification decisions (assignment of a particular descriptor to a particular subcategory and category) made by each judge independently with the external criterion. Table 1 presents mean validity coefficients for each subcategory and category: in the case of higher-order categories, kappa correlation coefficient ranged from .89 to .98 , and in the case of subcategories the lowest mean value was .72 for descriptors conveying pure evaluations. Given that what will matter in the successive stages of the procedure is the decision of the majority of judges, the validity of classification decisions should be regarded as satisfactory. It is also worth noting that in most psycholexical studies the psychometric verification of the validity of classification decisions is not performed.

We assessed inter-judge consistency (see Table 1) based on the classification of 9625 person-descriptive terms by computing the $\alpha$ coefficient as well as average correlations between the judges' decisions. Inter-judge consistency for higher-order categories ranged from .87 to .96 . In the case of subcategories, we obtained one value below .70 (social effects), while the remaining coefficients for specific subcategories ranged from .72 to .94 . The inter-judge consistency should be regarded as satisfactory and comparable to the values obtained in psycholexical studies conducted in other countries (cf. Angleitner et al., 1990; Hřebíčková, 2007; Mlačić \& Ostendorf, 2005).

\section{RESULTS}

The systematisation and psycholexical classification of Lithuanian person-descriptive terms showed that the lexicon of individual differences accounts for $14.70 \%$ of the vocabulary included in the dictionary of the Lithuanian language. As regards the size of linguistic categories in the set of person-descriptive terms, type-nouns constitute $39.96 \%$, attribute-nouns - $30.54 \%$, adjectives $-29.45 \%$, and participles - only $0.32 \%$ of individual differences.

Based on the decisions of the majority of judges (four out of six), $88.79 \%$ of the selected person-descriptive terms were classified into at least one higher-order category, and $79.27 \%$ were classified into at least one subcategory. The smaller percentage of words belonging to subcategories stems from the fact that the judges could agree on the choice of general category and disagree on the classification of a particular word into specific subcategories making up the higher-order category. Due to the ambiguity of some terms, $4.39 \%$ of words were classified into several higher-order categories, and the correspond- ing figure in the case of subcategories was $3.42 \%$. The results of psycholexical classification are presented in Table 2.

The largest group of individual differences in the Lithuanian vocabulary comprises words describing the social aspects of individual functioning (49.21\%). The most numerous lexical units in this category are type-nouns (2680 words) and adjectives (1145 words). The largest subcategory in the category of social and reputational aspects is words describing roles and relationships - they account for as many as $23.74 \%$ of person-descriptive terms. The second category in terms of frequency is dispositional descriptors, which constitute $18.90 \%$ of the lexicon of individual differences included in the dictionary, their dominant subcategory being temperament and character descriptors (13.65\%). Within this category, the largest group is adjectives (724 words), but other parts of speech are not far behind them in terms of frequency - dispositions are described by 599 attribute-nouns and 500 type-nouns. The third largest higher-order category is temporary conditions, comprising $11.84 \%$ person-descriptive terms, the largest subcategory being experiential states: emotions, moods, and cognitions (6.60\%). In Lithuanian, conditions are described mainly by means of attribute-nouns (848 items). Due to their ambiguity and specific usage context, the smallest category of person-descriptive terms is specific terms (3.12\%)

As mentioned above, dispositional traits - which are particularly interesting to scholars investigating individual differences - constitute the second largest group in Lithuanian. Table 3 contains the results of analysis concerning the semantic uniqueness and redundancy of words with an identical morpheme previously classified as personality descriptors.

In Lithuanian, there are dispositions that are morphemically unique, which means they have no counterparts with identical meaning among other parts of speech describing personality traits. The largest group of non-redundant descriptors is typenouns, which account for $7.53 \%$ of lexical items in the category of dispositions. The assessment of the proportion of these non-redundant type-nouns in the overall set of personality-descriptive terms indicates that they constitute $15.30 \%$ of all morphemes of words classified as personality traits. The second largest group is unique adjectives $(4.12 \%$ of dispositions, $8.40 \%$ of morphemes), whereas attribute-nouns account for only $0.66 \%$ of personality traits (1.30\% of morphemes). The next group of personality descriptors are traits referred to by at least two parts of speech with the same morpheme and semantic meaning. For instance, $16.05 \%$ of dispositions (32.70\% of morphemes) in Lithuanian are described at the same time by means of an adjective and an attribute-noun, $14.24 \%$ of dispositions $(29.00 \%$ of morphemes) are described by an adjective, an at- 
A. Ivanova, O. Gorbaniuk, D. Blèkaitytè, E. Dovydaitytè, A. A. Čepulienè, G. Mastauskaitè, R. Ramanauskas, U. Jurgelytè, R. Slapšinskaitè

Table 2

Classification of person-descriptive terms representing four types of lexical units

\begin{tabular}{|c|c|c|c|c|c|c|c|c|c|c|}
\hline \multirow[t]{2}{*}{ Category/subcategory } & \multicolumn{2}{|c|}{ Total } & \multicolumn{2}{|c|}{ Adjectives } & \multicolumn{2}{|c|}{ Participles } & \multicolumn{2}{|c|}{ Attribute-nouns } & \multicolumn{2}{|c|}{ Type-nouns } \\
\hline & $f$ & $\%$ & $f$ & $\%$ & $f$ & $\%$ & $f$ & $\%$ & $f$ & $\%$ \\
\hline 1. Dispositions & 1819 & 18.90 & 724 & 25.54 & 6 & 19.35 & 599 & 20.38 & 500 & 13.00 \\
\hline $\begin{array}{l}\text { 1a. Temperament and } \\
\text { character }\end{array}$ & 1314 & 13.65 & 539 & 19.01 & 5 & 16.13 & 420 & 14.29 & 357 & 9.28 \\
\hline 1b. Abilities and talents & 407 & 4.23 & 152 & 5.36 & 1 & 3.23 & 138 & 4.70 & 119 & 3.09 \\
\hline 2. Temporary conditions & 1140 & 11.84 & 178 & 6.28 & 5 & 16.13 & 848 & 28.85 & 114 & 2.96 \\
\hline 2a. Experiential states & 635 & 6.60 & 88 & 3.10 & 3 & 9.68 & 529 & 18.00 & 20 & .52 \\
\hline $\begin{array}{l}\text { 2b. Physical and bodily } \\
\text { states }\end{array}$ & 373 & 3.88 & 55 & 1.94 & 2 & 6.45 & 290 & 9.87 & 26 & .68 \\
\hline 2c. Observable activities & 92 & .96 & 23 & .81 & 0 & .00 & 12 & .41 & 63 & 1.64 \\
\hline $\begin{array}{l}\text { 3. Social and reputational } \\
\text { aspects }\end{array}$ & 4736 & 49.21 & 1145 & 40.39 & 13 & 41.94 & 908 & 30.89 & 2680 & 69.68 \\
\hline $\begin{array}{l}\text { 3a. Roles and } \\
\text { relationships }\end{array}$ & 2285 & 23.74 & 351 & 12.38 & 5 & 16.13 & 214 & 7.28 & 1719 & 44.70 \\
\hline 3b. Social effects & 164 & 1.70 & 88 & 3.10 & 0 & .00 & 57 & 1.94 & 20 & .52 \\
\hline 3c. Pure evaluations & 865 & 8.99 & 326 & 11.50 & 7 & 22.58 & 225 & 7.66 & 309 & 8.03 \\
\hline $\begin{array}{l}\text { 3d. Attitudes and } \\
\text { worldviews }\end{array}$ & 550 & 5.71 & 138 & 4.87 & 0 & .00 & 234 & 7.96 & 180 & 4.68 \\
\hline $\begin{array}{l}\text { 4. Overt characteristics } \\
\text { and appearance }\end{array}$ & 982 & 10.20 & 563 & 19.86 & 8 & 25.81 & 171 & 5.82 & 241 & 6.27 \\
\hline $\begin{array}{l}\text { 4a. Anatomy, constitution, } \\
\text { and morphology }\end{array}$ & 507 & 5.27 & 283 & 9.98 & 1 & 3.23 & 91 & 3.10 & 133 & 3.43 \\
\hline 4b Appearance and looks & 424 & 4.41 & 254 & 8.96 & 7 & 22.58 & 69 & 2.35 & 94 & 2.44 \\
\hline $\begin{array}{l}\text { 5. Specific terms: chronic } \\
\text { diseases and other } \\
\text { specialist terms }\end{array}$ & 300 & 3.12 & 42 & 1.48 & 0 & .00 & 196 & 6.67 & 63 & 1.64 \\
\hline 6. Metaphors & 809 & 8.41 & 227 & 8.01 & 0 & .00 & 194 & 6.60 & 390 & 10.14 \\
\hline 7. Non-classifiable & 44 & .46 & 14 & .49 & 1 & 3.23 & 8 & .27 & 21 & .55 \\
\hline $\begin{array}{l}\text { Not classified into any } \\
\text { of the categories }\end{array}$ & 1079 & 11.21 & 322 & 11.36 & 2 & 6.45 & 349 & 11.87 & 410 & 10.66 \\
\hline $\begin{array}{l}\text { Not classified into any } \\
\text { of the subcategories }\end{array}$ & 1995 & 20.73 & 577 & 20.35 & 2 & 6.45 & 573 & 19.50 & 847 & 22.02 \\
\hline$N$ & 9625 & 100.00 & 2835 & 100.00 & 31 & 100.00 & 2939 & 100.00 & 3846 & 100.00 \\
\hline
\end{tabular}

tribute-noun, and a type-noun, and $5.28 \%$ of personality traits $(10.80 \%$ of morphemes) are described by means of an adjective and a type-noun. The smallest group of redundant dispositions comprises $0.11 \%$ of descriptors $(0.20 \%$ morphemes) that are conveyed by four lexical items at the same time: an adjective, an attribute-noun, a type-noun, and a participle.

Turning to numbers of dispositions described by means of adjectives and other parts of speech, calculations reveal that in the group of dispositions there are as many as $18.90 \%$ of descriptors whose mor- phemes do not have adjectival counterparts. This means that nearly $20.00 \%$ of personality-descriptive terms in Lithuanian are outside the adjectival lexicon.

\section{DISCUSSION}

The systematisation and classification of terms describing individual differences in Lithuanian showed that the proportion of person-descriptive terms representing different parts of speech to the whole 
Table 3

Morphemically unique and redundant personality terms

\begin{tabular}{|c|c|c|c|c|c|}
\hline & \multirow[t]{2}{*}{ Part of speech } & \multicolumn{2}{|c|}{ Dispositional terms } & \multicolumn{2}{|c|}{ Dispositional morphemes } \\
\hline & & $f$ & $\%$ & $f$ & $\%$ \\
\hline \multirow{5}{*}{$\frac{\stackrel{0}{\partial}}{\frac{\sigma}{x}}$} & Unique adjective & 75 & 4.12 & 75 & 8.40 \\
\hline & Unique attribute-noun & 12 & 0.66 & 12 & 1.30 \\
\hline & Unique type-noun & 137 & 7.53 & 137 & 15.30 \\
\hline & Adjective and attribute-noun & 584 & 16.05 & 292 & 32.70 \\
\hline & Adjective and type-noun & 180 & 5.28 & 96 & 10.80 \\
\hline \multirow{5}{*}{ 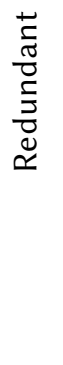 } & Attribute-noun and type-noun & 34 & 0.93 & 17 & 1.90 \\
\hline & Type-noun and participle & 6 & 0.16 & 3 & 0.30 \\
\hline & $\begin{array}{l}\text { Adjective and attribute-noun } \\
\text { and type-noun }\end{array}$ & 777 & 14.24 & 259 & 29.00 \\
\hline & $\begin{array}{l}\text { Adjective and participle, attribute-noun and } \\
\text { type-noun }\end{array}$ & 8 & 0.11 & 2 & 0.20 \\
\hline & Total & 1819 & 100.00 & 893 & 100.00 \\
\hline
\end{tabular}

lexicon included in the dictionary is similar to the corresponding proportion found in other languages whose taxonomy, apart from adjectives, also includes type-nouns and attribute-nouns. Lithuanian person-descriptive terms constitute $14.70 \%$ of the contents of the dictionary; the corresponding percentage is $14.01 \%$ for Hungarian (Szirmák \& De Raad, 1994), $11.97 \%$ for German (Angleitner, 1990), 10.32\% for Italian (Di Blas \& Forzi, 1998), and $17.70 \%$ for Croatian (Mlačić \& Ostendorf, 2005). A distinctive feature of Lithuanian compared to other examined natural languages seems to be different proportions of various parts of speech in the vocabulary of individual differences. In most languages, the group of person-descriptive terms with the largest number of words is adjectives (Angleitner, 1990; Gorbaniuk et al., 2014a; Szirmák \& De Raad, 1994). In Lithuanian, by contrast, this lexical group is only the third largest (29.45\%); the largest group describing individual differences is type-nouns (39.96\%), followed by attribute-nouns $(30.54 \%)$. This means that the Lithuanian lexicon of individual differences is dominated by nouns (accounting for $70.50 \%$ of the total pool of selected person-descriptive terms). The proportion of Lithuanian adjectives and nouns in the description of individual differences is consistent with the morphological structure of the language - for example, in the frequency lexicon of written Lithuanian (Utka, 2009) nouns constitute $39.37 \%$ and adjectives only $7.33 \%$ of words. The smallest group of terms describing individual differences is participles $(0.32 \%)$. This finding is consistent with Belarusian taxonomy (Gorbaniuk et al., 2014a); however, it does not necessarily mean that participles constitute a minor and insufficient group of person descriptors. In the pres- ent study, as well as in the study devoted to Belarusian, the number of participles partly stems from the structure of dictionaries; participles are easily formed from the verbs, and therefore few of them are included as separate entries.

From the point of view of psycholexical research, the most interesting group of person-descriptive terms is considered to be personality terms, being descriptors of those individual differences that are indicators of personality traits. The factor structures of personality lexicon are usually determined based on adjectives because it is adjectives that account for the highest number of terms describing relatively stable human characteristics significant from the psychological point of view (Ashton et al., 2004). This pattern is also true for the Lithuanian language - in the category of dispositions, the largest group is adjectives ( $39.80 \%$ of personality descriptors), but it is worth noting that other parts of speech are not far behind in number. Dispositional attribute-nouns account for as many as $32.93 \%$ of all dispositional descriptors in the Lithuanian personality lexicon included in the dictionary, and type-nouns account for $27.49 \%$.

Morphemic analysis of Lithuanian dispositional descriptors shows that nearly $20.00 \%$ of items in the personality lexicon do not have an adjectival form and are expressed by morphemically unique parts of speech. It is therefore worth asking whether this part of the personality lexicon describes the same characteristics as adjectives (thus being semantically redundant) or whether it describes other characteristics, not conveyed by adjectives. In light of the presented results, narrowing the list of dispositions down to the category of adjectives may re- 
sult in reductionism, which may lead to the omission of important personality dimensions in the process of determining the psycholexical structure of the language. What is more, expanding the list of dispositional adjectives to include other parts of speech and using this kind of comprehensive list may contribute to the identification of new dimensions that are specific to a particular culture or confirm the hypothesis about the universality of particular characteristics occurring in different natural languages. Consequently, the replicability of new traits in relation to the current Big Five (e.g., Peabody \& De Raad, 2002) or Big Six (e.g., Ashton et al., 2004) may be decisive to the change of beliefs regarding which dimensions meet the condition of universality and for which cultures particular human characteristics are universal.

\section{CONCLUSIONS}

The study presented in this paper is the first comprehensive taxonomy of the Lithuanian language, developed based on the dominant standards of psycholexical research: (1) we used what is currently the most reliable and representative source of the lexicon of individual differences; (2) we made the selection and classification of person-descriptive terms more objective (the procedure involving judges, the psychometric verification of the validity and consistency of classification decisions); (3) we used a comprehensive classification system (Angleitner et al., 1990), which constitutes the foundation for further multifaceted research on non-dispositional descriptors; and (4) we identified a comprehensive set of personality-descriptive terms, including all parts of speech (adjectives, type-nouns, and attribute-nouns). The list of descriptors obtained as a result of analyses can be used to determine the structure of the personality lexicon of the Lithuanian language, while the comprehensive taxonomy provides the foundation for further systematic research on the lexicon of individual differences, e.g. on the structure of the complete personality lexicon in the non-restrictive approach (De Raad \& Barelds, 2008), the structure of the personality lexicon of type-nouns (Saucier, 2003) or attribute-nouns (Di Blas, 2005), and the lexicon of non-dispositional individual differences such as emotional states (Gorbaniuk \& Macheta, 2017), social effects (Mlačić, 2016; Saucier, 2010), or worldview (see Saucier, 2013) in Lithuanian.

\section{ACKNOWLEDGMENTS}

This paper is partly supported by a National Science Centre grant (Poland) [registration number 2017/25/N/HS6/02210] to Ana Ivanova.

\section{ReFERENCES}

Allport, G. W., \& Odbert, H. S. (1936). Trait names: A psycho-lexical study. Psychological Monographs, 47, 1-171.

Angleitner, A., Ostendorf, F., \& John, O. P. (1990). Towards a taxonomy of personality descriptors in German: A psycho-lexical study. European Journal of Personality, 4, 89-118.

Ashton, M. C., Lee, K., \& Goldberg, L. R. (2004). A hierarchical analysis of 1,710 English personality-descriptive adjectives. Journal of Personality and Social Psychology, 87, 707-721.

Brokken, F. B. (1978). The Language of Personality. Krips: Meppel.

Caprara, G. V., \& Perugini, M. (1994). Personality described by adjectives: the generalizability of the Big Five to the Italian lexical context. Journal of Personality, 8, 357-369.

Cattel, R. B. (1945). The description of personality: Principles and findings in a factor analysis. The American Journal of Psychology, 58, 69-90.

De Raad, B., \& Ostendorf, F. (1996). Quantity and quality of trait-descriptive type nouns. European Journal of Personality, 10, 45-56.

De Raad, B., \& Barelds, D. P. H. (2008). A new taxonomy of Dutch personality traits based on a comprehensive and unrestricted list of descriptors. Journal of Personality and Social Psychology, 94, 347-364.

De Raad, B., \& Mlačić, B. (2017). Psycholexical studies of personality structure across cultures. In A. T. Church (Ed.), The Praeger Handbook of Personality across cultures. Trait psychology across cultures (Vol. 1, pp. 161-192). Santa Barbara, Denver: Praeger.

Di Blas, L., \& Forzi, M. (1998). An alternative taxonomic study of personality-descriptive adjectives in the Italian language. European Journal of Personality, 12, 75-101.

Di Blas, L. (2005). Personality-relevant attribute-nouns: A taxonomic study in the Italian language. European Journal of Personality, 19, 537-557.

Eysenck, H. J. (1953). The structure of human personality. London: Methuen.

Galton, F. (1884). Measurement of character. Fortnightly Review, 36, 179-185.

Goldberg, L. R. (1981). Language and individual differences: The search for universals in personality lexicons. In L. Wheeler (Ed.), Review of personality and social psychology (Vol. 2, pp. 141-165). Beverly Hills, CA: Sage.

Goldberg, L. R. (1982). From ace to zombie: Some explorations in the language of personality. In C. D. Spielberger \& J. N. Butcher (Eds.), Advances in Personality Assessment (Vol. 1, pp. 203-234). Erlbaum: Hillsdale. 
Goldberg, L. R. (1990). An alternative "description of personality": The Big-Five factor structure. Journal of Personality and Social Psychology, 59, 1216-1229.

Gorbaniuk, O., \& Macheta, K. (2017). Psycholexical taxonomy of emotional states: the study of Polish language. Closer to Emotions Conference, Lublin, 18-19.05.2017.

Gorbaniuk, O., Czarnecka, E., \& Chmurzyńska, M. (2011). Taxonomy of Person-Descriptive Terms in Polish: A Psycho-Lexical Study. Current Problems of Psychiatry, 12, 100-106.

Gorbaniuk, O., Kulewicz, P., Gorbaniuk, J., Kordon, A., Leoszko, W., Ivanova, A., \& Suchomska, M. (2014a). Taksonomia psycholeksykalna języka biatoruskiego. Current Problems of Psychiatry, 15, 89-95.

Gorbaniuk, O., Mirovich, A., Leoshko, W., Gorbaniuk, J., Kordon, A., \& Ivanova, A. (2014b). Taksonomia psycholeksykalna języka ukraińskiego. III Ogólnoukraiński Kongres Psychologiczny. Instytut Psychologii im. G. S. Kostiuka Ukraińskiej Akademii Nauk 2014, Kijów, 20-21.11.2014.

Hofstee, W. K. B. (1976). Dutch traits: The first stages of the Groningen taxonomy study of personality descriptive adjectives. University of Groningen, The Netherlands.

Hřebíčková, M. (2007). The lexical approach to personality description in the Czech context. Chechoslovak Psychology, 51, 50-61.

Ivanova, A., Gorbaniuk, O., Kordon., A., Gorbaniuk, J., Leoszko, W., \& Kulewicz, P. Języki wschodniostowiańskie: aktualne problemy wspótczesnej lingwistyki. XVIII Międzynarodowa Konferencja Slawistyczna „Literatury, kultury i języki wschodniosłowiańskie wobec swego czasu historycznego". Zielona Góra, 22-23.05.2017.

John, O. P., Angleitner, A., \& Ostendorf, F. (1988). The lexical approach to personality: A historical review of trait taxonomic research. European Journal of Personality, 2, 171-203.

Livaniene, V., \& De Raad, B. (2017). The factor structure of Lithuanian personality-descriptive adjectives of the highest frequency of use. International Journal of Psychology, 52, 453-462.

Mlačić, B., \& Ostendorf, F. (2005). Taxonomy and structure of Croatian personality-descriptive adjectives. European Journal of Personality, 19, 117-152.

Mlačić, B. (2016). Social and reputational aspects of personality. International Journal of Personality Psychology, 2, 15-36.

Norman, W. T. (1967). 2,800 personality trait descriptors: Normative operating characteristics for a university population. Department of Psychology, University of Michigan; Ann Arbor Research Rep. Nr 08310-1-T.

Quirk, R., Greenbaum, S., Leech, G., \& Svartvik, J. (1972). A Grammar of Contemporary English. Singapore: Longman.
Peabody, D., \& Goldberg, L. R. (1989). Some determinants of factor structures from personality-trait descriptors. Journal of Personality and Social Psychology, 57, 552-567.

Peabody, D., \& De Raad, B. (2002). The substantive nature of psycholexical personality factors: A comparison across languages. Journal of Personality and Social Psychology, 83, 983-997.

Saucier, G. (1997). Effects of variable selection on the factor structure of person descriptors. Journal of Personality and Social Psychology, 73, 1296-1312.

Saucier, G. (2003). Factor structure of English-language personality type-nouns. Journal of Personality and Social Psychology, 85, 695-708.

Saucier, G. (2010). The structure of social effects: Personality as impact on others. European Journal of Personality, 24, 222-240.

Saucier, G. (2013). Isms dimensions: Toward a more comprehensive and integrative model of belief-system components. Journal of Personality and Social Psychology, 104, 921-939.

Saucier, G., \& Srivastava, S. (2015). What makes a good structural model of personality? Evaluating the Big Five and alternatives. In M. Mikulincer, P. R. Shaver, M. L. Cooper, \& R. J. Larsen (Eds.), APA handbook of personality and social psychology, Vol. 4: Personality processes and individual differences (pp. 283-305). Washington, DC, US: American Psychological Association.

Szirmák, Z., \& De Raad, B. (1994). Taxonomy and structure of Hungarian personality traits. European Journal of Personality, 8, 95-117.

Truskauskaitè-Kunevičienè, I., Kaniušionytè, G., Kratavičienè, R., \& Kratavičiūtè-Ališauskienè, A. (2012). Psychometric properties of the Lithuanian versions of HEXACO-100 and HEXACO-60. Educational Psychology, 23, 6-14.

Utka, A. (2009). Dažninis rašytinès lietuvių kalbos žodynas. Kaunas: Vytauto Didžiojo Universitetas, Humanitarinis fakultetas, Kompiuterinès lingvistikos centras.

Wierzbicka, A. (1986). What's in a noun? (Or: how do nouns differ in meaning from adjectives?). Studies in Language, 10, 353-389.

Žukauskiené, R., \& Barkauskienè, R. (2006). Lietuviškosios NEO PI-R versijos psichometriniai rodikliai. Psichologija, 33, 7-21. 